\title{
Cloning and Characterization of 13 Novel Transcripts and the Human RGS8 Gene from the 1q25 Region Encompassing the Hereditary Prostate Cancer (HPC1) Locus
}

\author{
Raman Sood,,$^{, 1,2}$ Tom I. Bonner,,$^{, 1}$ Izabela Makalowska, $\ddagger$ Dietrich A. Stephan,* \\ Christiane M. Robbins,* Tim D. Connors,§ Sharon D. Morgenbesser,§ Kui Su,§ \\ Mezbah U. Faruque,* Heather Pinkett,* Chris Graham,* Andreas D. Baxevanis, $\neq$ \\ Kathy W. Klinger,§ Greg M. Landes,§ Jeffrey M. Trent,* and J ohn D. Carpten* \\ * Cancer Genetics Branch and ¥Genome Technology Branch, National Human Genome Research Institute, and †Laboratory \\ of Genetics, National Institute of M ental Health, National Institutes of Health, Bethesda, Maryland 20892; \\ and §Genzyme Genetics Corporation, Framingham, Massachusetts 01701
}

Received November 6, 2000; accepted January 12, 2001

The aim of this study was to develop a saturated transcript map of the region encompassing the HPC1 locus to identify the susceptibility genes involved in hereditary prostate cancer (OMIM 176807) and hyperparathyroidism-jaw tumor syndrome (OMIM 145001). We previously reported the generation of a 6-Mb BAC/PAC contig of the candidate region and employed various strategies, such as database searching, exon-trapping, direct cDNA hybridization, and sample sequencing of BACs, to identify all potential transcripts. These efforts led to the identification and precise localization on the BAC contig of 59 transcripts representing 22 known genes and 37 potential transcripts represented by ESTs and exon traps. Here we report the detailed characterization of these ESTs into full-length transcript sequences, their expression pattern in various tissues, their genomic organization, and their homology to known genes. We have also identified an Alu insertion polymorphism in the intron of one of the transcripts. Overall, data on 13 novel transcripts and the human RGS8 gene (homologue of the rat RGS8 gene) are presented in this paper. Ten of the 13 novel transcripts are expressed in prostate tissue and represent positional candidates for HPC 1. Academic Press

Sequence data from this article have been deposited with the EMBL/GenBank Data Libraries under Accession Nos. AF288389AF 288399, AF 297014-AF 297023, AF 338436, and AF 312863AF 312865.

${ }^{1}$ These authors contributed equally to this work.

2 To whom correspondence should be addressed at NHGRI, NIH, Building 36, Room 3D05, 9000 Rockville Pike, Bethesda, MD, 20892. Telephone: (301) 435-5746. Fax: (301) 435-5465. E-mail: rsood@nhgri.nih.gov.

\section{INTRODUCTION}

Prostate cancer (OMI M 176807) is a complex disease involving multiple susceptibility loci as evident from genome-wide linkage scans performed over the past 4 years following the identification of the HPC1 locus by our laboratory (Smith et al., 1996). Several loci, including three on chromosome 1 designated HPC1 (1q24q31, Smith et al., 1996; Cooney et al., 1997; Neuhausen et al., 1999), PcaP (1q42, Berthon et al., 1998), and CAPB (1p36, Gibbs et al ., 1999), the HPCX locus on the X chromosome (Xu et al., 1998), and one each on chromosomes 2q, 12p, 15q, 16p, and 16q (Suarez et al., 2000), and 20q13 (Berry et al., 2000), have been implicated to contain potential prostate cancer susceptibility genes. Recently Rebbeck et al. (2000) reported the association between two common missense variants in the HPC2/ELAC2 gene and prostate cancer risk. Despite extensive molecular studies, no gene has been identified yet that would help elucidate the underlying mechanisms responsible for hereditary prostate cancer. It is difficult to draw any conclusions about the nature of the genetic defect involved in HPC1-associated prostate cancer cases based on existing cytogenetic data. There is no evidence of gross cytogenetic rearrangements involving the $\mathrm{HPCl}$ candidate region. Furthermore, loss of heterozygosity studies at the HPCl locus have shown that the loss of wildtype allele, which is a hallmark of classic tumor suppressor genes, is very rare in both familial and sporadic cases of prostate cancer (Latil et al., 1997; Dunsmuir et al., 1998; Ahman et al., 2000). There are no reports of loss at 1q24-q31 by comparative genomic hybridization $(\mathrm{CGH})$ in sporadic prostate cancer cases (Visakorpi et al., 1995; Sattler et al., 1999). H owever, there has been one report of gain of $1 q$ by $\mathrm{CGH}$, suggesting the possible involvement of an oncogene (Cher et al., 1996). 
Our laboratory has focused on the identification of the HPCl gene using a positional cloning strategy. We have developed a sequence-ready BAC/PAC contig covering $6 \mathrm{Mb}$ of the HPClcandidate region, which served as a template to identify and map 22 known genes and 37 potential transcripts (Carpten et al., 2000). Several known genes and ESTs were identified from the human gene map and mapped to the contig at high resolution. In addition, we used BAC and PAC clones as templates to identify unmapped ESTs and potential coding sequences by exon-trapping, shotgun sequencing, and direct screening of CDNA libraries. All ESTs and exon traps representing potential transcripts were characterized for their expression profiles using $\mathrm{N}$ orthern blot analysis. We have extended several partial cDNA sequences into near full-length clones through a combination of gene-trapper (LTI) and RACE (Clontech) techniques, in addition to assembly and editing of EST sequences from GenBank. The characterization of these potential transcripts will provide not only candidate genes for HPC1 but also HRPT2 (hyperparathyroidism-jaw tumor syndrome; OMIM 145001), which has been mapped to the same chromosomal region (Teh et al., 1996; Hobbs et al., 1999; Williamson et al., 1999).

\section{MATERIALS AND METHODS}

Transcript identification and mapping. Details of the clone-based physical map and identification of transcripts are described elsewhere (Carpten et al., 2000). Briefly, transcripts were identified by database searches utilizing human gene maps (http://www.ncbi.nlm. nih.gov/genemap/), exon-trapping of BAC clones representing the minimal tiling path, sample sequencing of selected BAC clones followed by computational analysis, and also direct hybridization of high-density nylon filters arrayed with IMAGE cDNA clones (Research Genetics) with radiolabeled BAC inserts. For details of these methods, please refer to our earlier publication (Carpten et al., 2000). All potential transcripts were precisely placed on the physical map either by PCR (polymerase chain reaction) or by Southern blotting of BAC clones followed by hybridization with inserts from available cDNA clones.

Northern analysis. Northern blots with mRNA from multiple human tissues including prostate (MTN4) were purchased from Clontech. To determine the transcript size(s) and tissue distribution pattern of potential transcripts, MTN4 blots were hybridized with either gel-purified inserts from available IMAGE CDNA clones or PCR products generated from cDNA libraries (Clontech). The latter was used if no IMAGE clone was available or if available clones contained a repeat element such as Alu or L1. The probes were labeled with $\left[{ }^{32} \mathrm{P}\right] \mathrm{dCTP}$ by random priming (Stratagene) following the manufacturer's directions. Hybridization was carried out at $42^{\circ} \mathrm{C}$ overnight in Hybrisol 1 hybridization buffer (Intergen) followed by stringent washing in $0.1 \% S D S, 0.1 \times \mathrm{SSC}$ at $65^{\circ} \mathrm{C}$. Autoradiography was performed for the appropriate time period at $-80^{\circ} \mathrm{C}$ with a BioMax intensifying screen and film.

cDNA library screening by GeneTrapper. L onger CDNA clones for potential transcripts were identified using the Gene Trapper cDNA Positive Selection System (Life Technologies) following the manufacturer's directions. Briefly, oligonucleotides designed from partial CDNA sequences representing exon traps or ESTs were synthesized and PAGE-purified (L ofstrand Labs). These oligonucleotides were then biotinylated and hybridized to single-stranded DNA from adult and fetal brain, liver, spleen, leukocytes, kidney, heart, lung, and testis cDNA libraries. Hybrids were captured using paramagnetic streptavidin beads, and double-stranded cDNA was reconstructed using another gene-specific oligonucleotide downstream of that used in the initial hybridization reaction. Positive clones were identified by transformation of resulting double-stranded DNA into Escherichia coli, followed by PCR amplification of recombinant clones using gene-specific primers.

Rapid amplification of cDNA ends (RACE). 5'-RACE was performed using the Marathon-Ready RACE system (Clontech) according to their specifications. Marathon-Ready cDNA libraries derived from fetal and adult brain, prostate, testis, liver, leukocytes, and spleen were used as templates for RACE reactions. Typically, three antisense gene-specific primers were designed from the partial cDNA sequence. Adaptor primer AP1 was used in the primary RACE reaction with each of the two most $3^{\prime}$ primers. RACE reactions were purified from unincorporated nucleotides and primers using the QI Aquick PCR purification kit (Qiagen) and then used as template for secondary RACE reactions using the AP 2 adaptor primer and nested gene-specific primers. Products were cloned using the TOPO TA cloning kit (Invitrogen).

Clone characterization. All IMAGE clones, positive Gene-Trapper clones, and RACE clones were processed as follows: DNA was extracted from a 3-to 5-ml overnight bacterial culture using the Wizard Plus Minipreps DNA Purification System (Promega). Clones were sequenced using primers from both ends of the vector followed by walking primers designed from the initial sequence data. DNA sequencing reactions were performed using $\sim 0.5 \mu \mathrm{g}$ DNA per reaction and the PE Biosystems FS+ and Big Dye Terminator chemistry (Robbins et al., 1996) and were analyzed on a PE Biosystems 377 XL DNA Sequencer.

Computer analysis. Sequences were assembled into contigs and analyzed for open reading frames using Sequencher, v3.1 (Gene Codes). When available (ftp//:genome.wustl.edu/pub/gsc/est/), trace data for ESTs were incorporated and manually edited to remove base-calling errors. Sequence homology to previously characterized DNA and protein sequences in the $\mathrm{nr}$ and dbEST sections of GenBank was determined using the BLAST algorithm (Altschul et al., 1990) accessible from the NCBI home page (http://www.ncbi.nlm.nih. gov/). A reiterative process of assembly and BLAST searches allowed extension of many ESTs well beyond the ends of Unigene clusters. We have submitted the sequences of all characterized transcripts to GenBank, and the accession numbers are provided for further reference (Table 2). Protein sequences predicted from the cDNAs were analyzed for motifs using I nterpro (http://www.ebi.ac.uk/interpro/).

\section{RESULTS}

We used a combination of exon-trapping, cDNA library screening with BAC inserts, and shotgun sample sequencing in addition to the information available in the public databases, particularly the human gene maps (Deloukas et al., 1998), to identify transcribed sequences from the region encompassing the HPCl locus at $1 q 25$. These efforts identified 22 known genes and 37 ESTs that were localized to the 6-M b BAC/PAC contig (Carpten et al., 2000). F urther characterization of the ESTs was performed as follows: U nigene clusters were used to assemble maximum available sequence information, and IMAGE clones for the largest available clone in each cluster were purchased (Research Genetics) and sequenced to verify the clone and to obtain the sequence of the entire insert. The sequences were searched for a putative polyadenylation signal (AATAAA or with minor variation as described by Beaudoing et al., 2000) and database homologies to any known genes or domains indicative of potential coding sequence. Since our tissue of interest has been pros- 
TABLE 1

Sequence Features of ESTs Not Expressed in Tissues on MTN4 Blot

\begin{tabular}{|c|c|c|c|c|c|}
\hline Name & Accession No. & Unigene Cluster ID & Sequenced length (bp) & Poly $(A)$ signal & Characteristics of available sequence \\
\hline AA757084 & AA757084 & None & 486 & $\begin{array}{l}\text { Yes } \\
\text { (AGTAAA) }\end{array}$ & Single EST, no other hits \\
\hline el0 & T97314 & Hs. 18033 & 1300 in 3 fragments & Yes & Single EST \\
\hline & AF 075081 & Hs. 36300 & 589 & No & No ORF \\
\hline AA431804 & AA431804 & None & 546 & $\begin{array}{l}5^{\prime} \text { end } \\
\text { sequenced }\end{array}$ & Overlaps with a mouse EST \\
\hline e9 & T79647 & None & 513 & No & Single EST, no other hits \\
\hline e4 & R48958 & Hs. 221535 & 940 in 2 fragments & No & No ORF \\
\hline e13 & H92337 & None & 434 & No & Single EST, repeat sequence \\
\hline ge27 & AA657406 & None & 439 & No & $\begin{array}{l}\text { Identified by an exon trap, intronic } \\
\text { sequence on both sides of the exon }\end{array}$ \\
\hline e5 & M78545 & None & 276 & $\begin{array}{l}5 \text { ' end } \\
\text { sequenced }\end{array}$ & Single EST, no other hits \\
\hline AA744170 & AA744170 & None & 305 & No & Single EST, no other hits \\
\hline IC-145842 & $\mathrm{R} 79368$ & Hs. 144508 & 930 & Yes & $\begin{array}{l}5^{\prime} \text { end contains Alu sequence May } \\
\text { represent alternate } 3^{\prime} \text { end of PLA2 }\end{array}$ \\
\hline IC-123336 & R00375 & None & 710 & No & Repeat sequence \\
\hline Z39494 & Z39494 & Hs. 65765 & 316 & No & No other hits \\
\hline M78285 & M78285 & None & 442 & Yes & Single EST, no other hits \\
\hline M78354 & M78354 & None & 352 & Yes & Single EST, no other hits \\
\hline
\end{tabular}

tate, we hybridized inserts from these clones to MTN4 Northern blots (Clontech) to determine both the size and the tissue-specificity of the expected transcripts. ESTs were prioritized for further characterization based on a positive signal on the Northern blots and the presence of a polyadenylation signal, indicative of the ESTs representing authentic cDNAs.

Of the 37 candidate ESTs, 15 failed to meet our criteria and were not characterized further (Table 1). Apart from background signals or smear, no clear bands were observed on MTN4 Northern blots for any of these ESTs. Furthermore, their initial characterization showed most of them to be represented by a single cDNA clone. Eight of these ESTs also lacked a polyadenylation signal, thereby suggesting that they may have been primed on the A-rich stretches of intronic sequences, representing artifacts of cDNA cloning (Wolfsberg and Landsman, 1997). We were particularly interested in ge27, since it was identified by an exon trap and the EST is derived from a prostate CDNA library. However, repeated attempts at 5'-RACE yielded only products that matched genomic sequence. These data indicate that a large proportion of these ESTs represent artifacts of CDNA cloning. However, the remaining few might represent transcripts expressed in tissues other than those on MTN4 Northern blots and, therefore, need to be analyzed further, particularly for their expression in parathyroid gland and kidney, to be considered as candidates for HRPT2 syndrome.

Of the remaining 22 ESTs, data on the detailed characterization of 19 transcripts are presented below. KIAA0959/e3 was found to represent the human homologue of mouse RGL, a protein involved in the Ras signaling pathway, and has been described elsewhere (Sood et al., 2000). Similarly, Z47, an 18-kb cDNA representing a human homologue of the Caenorhabditis el egans hemicentin gene him-4 has been characterized extensively and will be described elsewhere (manuscript in preparation). The EST e19 was found to encode the 3'-UTR of the voltage-dependent calcium channel $\alpha-1 \mathrm{E}$ subunit (GenBank Accession No. L29384), a known gene that we had previously mapped to the same set of overlapping BAC clones.

Two methods of transcript extension, the Gene-Trapper Positive cDNA Selection System (LTI) and 5'RACE (Clontech), were used in extending these 19 ESTs to full-length transcripts. High GC 5'-RACE has also been used in some cases to identify GC-rich 5' ends. The method of choice for cDNA extension was based upon the results of screening a panel of Marathon-Ready cDNA libraries (Clontech) and superscript cDNA libraries (LTI) from a variety of tissues. Resulting clones were sequenced and assembled with the data from the Unigene cluster using Sequencher. The cDNA and deduced amino acid sequences of all transcripts were used to search for any homologous sequences in GenBank using the BLAST programs. These analyses showed that 13 of the 19 transcripts are novel, 2 are homologous to previously cloned genes, 2 are redundant with others, and 2 most likely represent artifacts. Figure 1 shows the position of these transcripts relative to one another and genetic markers from the 1q25 region. The orientation of these transcripts was determined either by PCR using primers from 5' and 3' ends of the cloned sequence against the BAC contig or by alignment of the CDNA sequences with genomic sequences and is shown by the arrow. Transcripts c190 and c78 as well as the ESTs Z39494, M 78285, and M78354 map telomeric of D1S1642. Table 2 lists various characteristics of these transcripts, including the expected size from Northern blot analy- 
sis, cloned size and length of the open reading frame (ORF), database similarities to known genes from various organisms, and genomic organization. The transcripts are listed in centromeric to telomeric order.

\section{Expression Profiles of Novel Transcripts}

The expression profiles of the novel genes were examined with eight different human tissues, including prostate. Representative Northern blots showing the transcript size and tissue distribution pattern for eight transcripts are presented in Fig. 2. The data are also summarized in Table 2. Ten transcripts showed expression in prostate; however, none revealed a prostate-specific expression pattern. Seven of the 10 were found to be expressed to varying degrees in all the tissues examined, suggesting that these genes are expressed ubiquitously. z28 was found to be expressed in three alternative forms in all tissues except peripheral blood leukocytes, with the largest form (4.2 kb) being the most abundant. Hybridization signals for 3 transcripts were observed in testis only, with ge36 being very strong, whereas e15 and KIAA0479/e20/c37 were detected at low levels. Low-level expression in testis is often seen even for transcripts specifically expressed in other tissues. Therefore, e15 and e20 may not be testisspecific genes but expressed in tissues not examined in this study. The fact that the KIAA0479 sequence was derived from a cDNA clone originating from a brain cDNA library suggests that KIAA0479/e20/c37 may be a brain-specific transcript. Hybridization of MTN1 Northern blot with a probe derived from this transcript revealed that KIAA0479/e20/c37 has strong expression in brain as well as weak expression in placenta (data not shown).

\section{Sequence Characteristics of Novel Transcripts}

Sequence analysis has shown 13 of the 19 transcripts to be novel, with varying degrees of homology to proteins from other species. Sequencing of random CDNA clones with large inserts (RIKEN project and KIAA series initiated by Ohara et al., 1997) has also identified partial sequences for several of our transcripts. These transcripts are indicated by names comprising database name/est or contig number assigned to all our ESTs as an identifier (Table 2), e.g., KIAA0584/c33/c47 (Nagase et al., 1998), KIAA0250/c48 (Nagase et al., 1996), and KIAA0479/e20/c37 (GenBank Accession No. AB007948). In all cases, our data provide either additional coding sequence at 5 ' ends or detailed expression profiles. New accession numbers were obtained only if our sequence provided additional data; e.g., the e20/c37 sequence is longer than the KIAA0479 sequence and provides additional data at the $5^{\prime}$ end.

Our z28 cDNA (not submitted to GenBank) corresponds to two overlapping cDNA sequences, AK 000512 and AK 000171, which differ in their utilization of polyadenylation sites and an insertion of A near the $3^{\prime}$ end of the coding sequence. There are eight As in the 


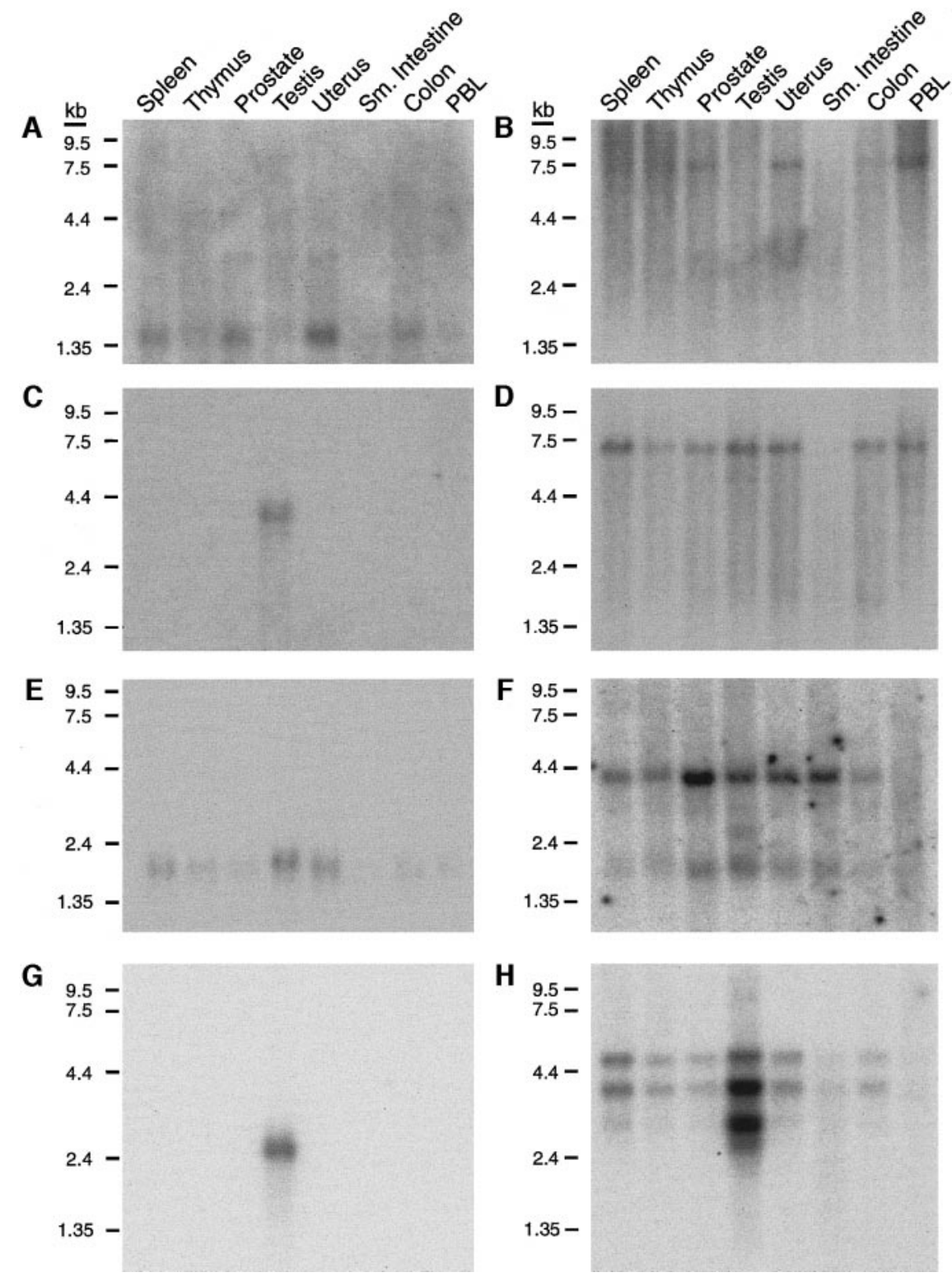

FIG. 2. Northern blot analysis of eight transcripts from the HPCl candidate region. Multiple tissue Northern blots (Clontech) containing $\operatorname{poly}(\mathrm{A})^{+}$mRNA of eight adult human tissues, as indicated at the top of each lane, were hybridized with ${ }^{32} \mathrm{P}-\mathrm{label}$ ed $\mathrm{cDN}$ A probes specific for e8 (A), el1 (B), e15 (C), el6 (D), e17 (E), z28 (F), ge36 (G), and ge42 (H). Size markers are indicated on the left side of each blot. Blots were autoradiographed for $1-5$ days at $-80^{\circ} \mathrm{C}$.

AK 000171 sequence versus nine As in the AK 000512 sequence. The $(A)_{8}$ allele gives an open reading frame that extends 360 bases farther $3^{\prime}$ than that of the $(A)_{9}$ allele. We analyzed DNA from 12 individuals by sequencing an amplimer of 414 bp containing the pre sumed polymorphic site and failed to observe any chromosome with the $(A)_{9}$ allele. Analysis of the genomic sequences in the htgs database identifies two BAC clones (GenBank Accession Nos. AL162722 and AL 162723), both with the $(A)_{8}$ allele. The only other sequence with the $(A)$, allele is an EST sequence (GenBank Accession No. AA085997). These data suggest that the $(A)$, allele represents either a rare allele or a sequencing error/cloning artifact.

We have cloned the complete coding region for e8/ c24, e20, c78, z28/c7, ge36, and ge42, as evidenced by the presence of in-frame termination codons upstream of the first ATG in these six transcripts. F urthermore, Northern blot data indicate that almost the complete coding sequence has been obtained for ell, el5, and e17. The ATG coding for the initiating methionine lies in the optimal context for initiation of translation as suggested by Kozak (1996) in these three transcripts, further supporting the conclusion that we have identified the complete coding sequence for these transcripts.

\section{Known Genes}

Homology searches with one of our ESTs (c78) identified a known gene, B3GalT2 (GenBank Accession No. 


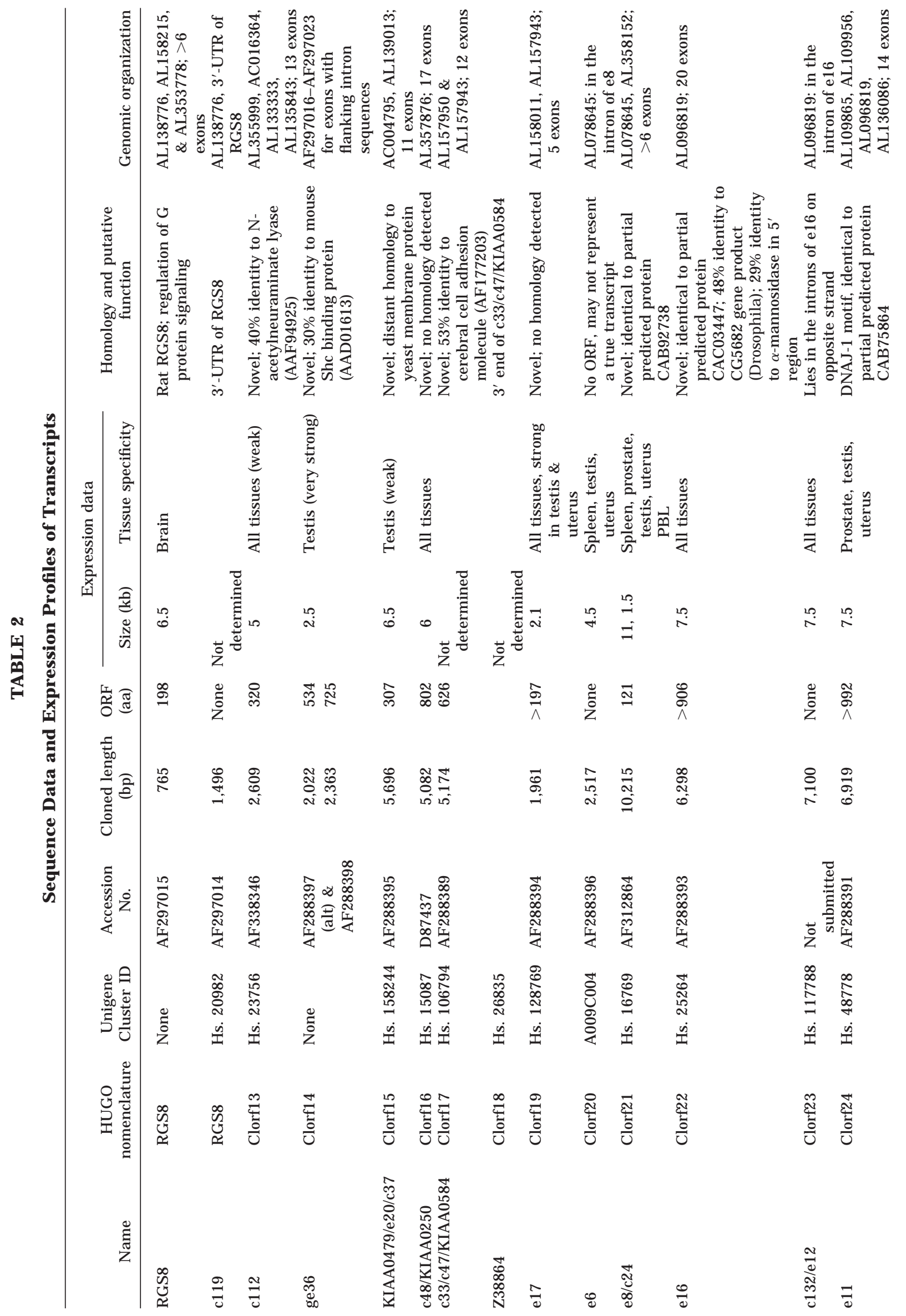



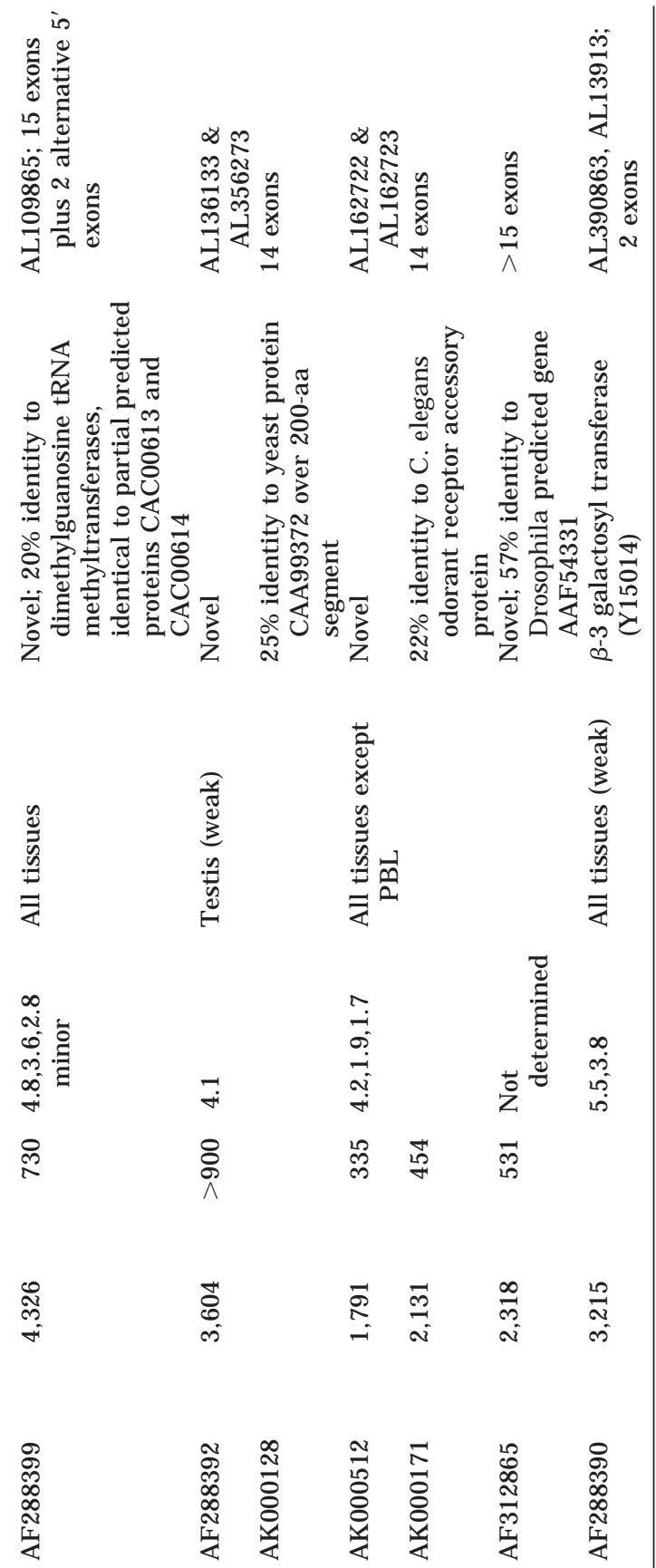

$\stackrel{0}{\frac{0}{2}}$



$\stackrel{ }{\stackrel{4}{0}}$

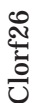

$\stackrel{\Uparrow}{\frac{t}{2}}$

Y 15014), which belongs to a family of human $\beta$-3-galactosyltransferases involved in the synthesis of type 1 carbohydrate chains (Kolbinger et al., 1998). It should be noted that the $5^{\prime}-U T R$ sequence of this transcript identified by us (GenBank Accession No. AF 288390) is different from the published 5'-UTR sequence of B3GalT2 (Accession No. Y 15014). BLAST analysis against the GenBank htgs database finds our $5^{\prime}$ sequence in the same BAC that contains the remainder of the gene (GenBank Accession No. AL 139133). In contrast, the first 482 bp from Y 15014 do not match with any genomic sequence, indicating either an alternative $5^{\prime}$ exon or a cloning artifact.

\section{Human Homologue of RGS8}

One of the exon traps from BAC 270B 19 was found to be homologous to rat RGS8 (GenBank Accession No. AB006013), a gene involved in the regulation of Gprotein signaling (Saitoh et al., 1997). 5'-RACE was performed to clone the complete coding sequence for human RGS8. Several alternatively spliced 5'-RACE products were analyzed to identify the one with the largest open reading frame of 198 amino acids (GenBank Accession No. AF 297015). This sequence represents an alternatively spliced mRNA compared to the rat sequence and the recently submitted human RGS8 coding sequence (GenBank Accession No. AF 300649), resulting in a protein with a different amino terminus (Fig. 3A). Alignment of the three cDNAs against unfinished human genomic sequences (GenBank Accession No. AL353778) shows that they are all derived from seven exons, with the rat CDNA containing exons 2 through 7, the short form of human RGS8 containing exons 3 through 7, and the long form lacking exon 3. The initiation codon (ATG) lies in exon 3 of the rat and the short form of the human RGS8 sequences. The long form of human RGS8 has its first ATG in exon 1. However, translation may initiate at the second ATG that lies in exon 2, since the first ATG has a poor Kozak sequence, containing a $C$ rather than an $A$ or a $G$ at the -3 position, which generally indicates poor initiation of translation (Kozak, 1996). The alignment of the human and rat RGS8 amino acid sequences shown in Fig. $3 A$ assumes translation initiation at the first ATG. Although we did not perform 3'-RACE, alignment of exon 7 of the coding sequence with the genomic sequence shows that the c119 cDNA sequence lies between 3.5 and $5 \mathrm{~kb}$ downstream of the termination codon of the RGS8 and may represent the $3^{\prime}$-UTR of RGS8. This would be consistent with the Northern blot data indicating that the size of the transcript is approximately $6.5 \mathrm{~kb}$ (Fig. 3B). Furthermore, Northern blot analysis using 16 different tissues present on MTN1 and MTN4 blots revealed expression of human RGS8 in brain only (Fig. 3B). Further analysis using a dot blot of 76 different tissues (MTE array from Clontech) showed the expression to be stronger in several subregions of the brain, particularly pons, putamen, thala- 

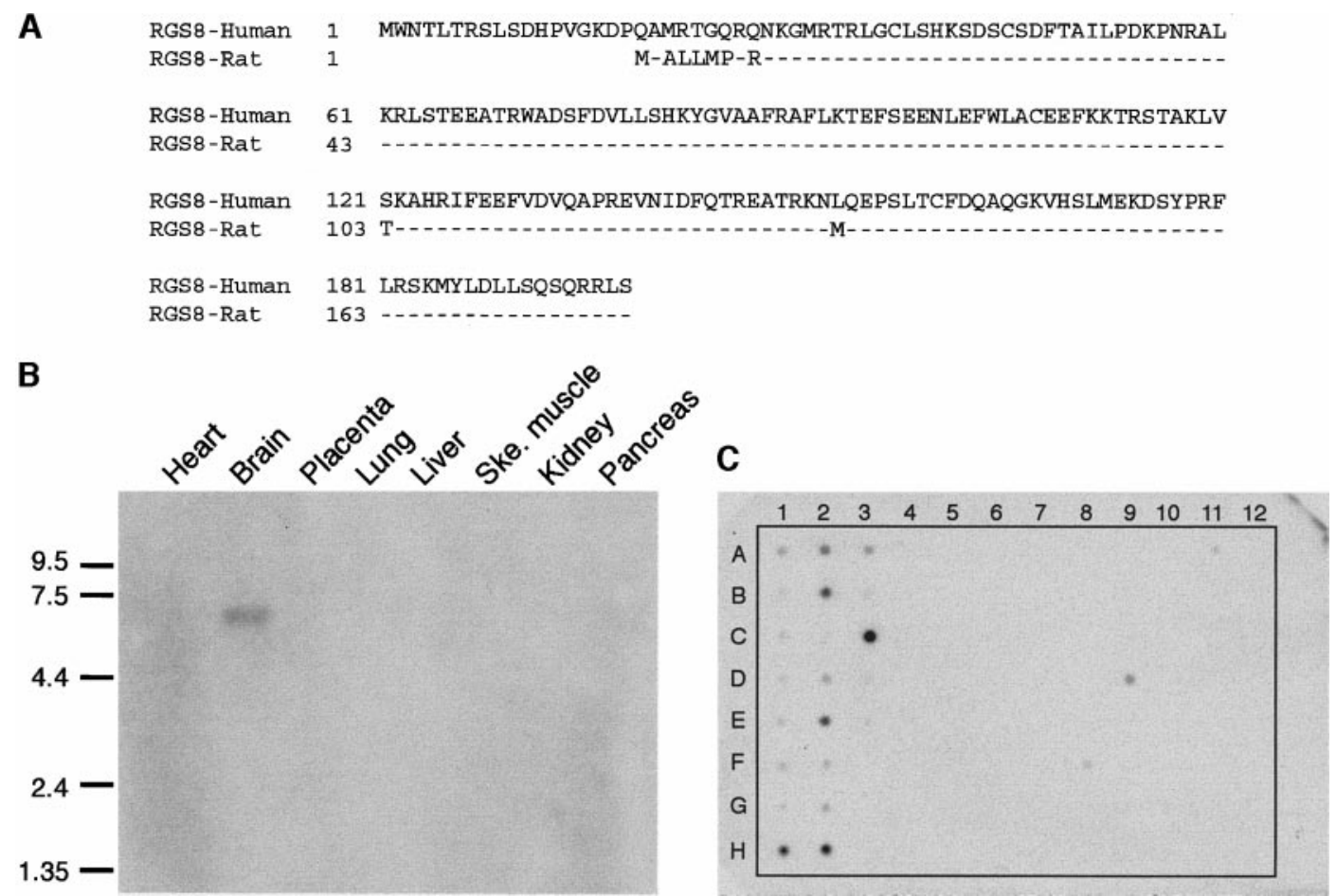

FIG. 3. Analysis of human RGS8. (A) Alignment of human and rat RGS8 at the amino acid level. Amino acids that differ between human and rat are shown in the rat sequence, a dashed line represents the identical residues. Amino acid numbering is given on the left side. (B) Northern blot analysis of the human RGS8 gene. Multiple tissue Northern blots (MTN1 and MTN4, Clontech) were hybridized with a ${ }^{32} \mathrm{P}$-labeled cDNA probe for RGS8. Autoradiograph for MTN4 is not shown due to lack of any signal. Molecular weight standards are indicated on the left. (C) Expression analysis of RGS8. Multiple tissue expression array (Clontech) containing poly(A) ${ }^{+}$RNA from 76 different human tissues was hybridized with the same probe as the MTN blots. Columns 1-3 contain various subregions of brain; position All contains fetal brain, $\mathbf{D 9}$ is thyroid gland, and $\mathbf{F} \mathbf{8}$ is testis.

mus, caudate nucleus, and cerebellum (Fig. 3C). In addition, a low level of expression is seen in fetal brain, testis, and thyroid gland.

\section{Genomic Organization}

The availability of genomic sequences, i.e., sequenced $B A C$ and PAC clones as a result of the Human Genome Project, has been a tremendous hel $p$ in determining the genomic organization of these transcripts. The last column of Table 2 lists the accession numbers for the genomic sequences that align with the transcripts and the number of exons in each transcript. Despite a positive signal on the Northern blots, several lines of evidence suggest that e6 and c132/e12 ESTs may not represent true transcripts. Not only do their sequences align with the genomic sequence uninterrupted (no splicing), they also lie in the introns of other transcripts (Fig. 1). Furthermore, we have assembled $7.1 \mathrm{~kb}$ of sequence for c132/e12 and $2.4 \mathrm{~kb}$ for e6, and no open reading frame is evident. The presence of el6 exons on the opposite strand of the c132/e12 sequence would explain the similar Northern signals observed using probes for both of these ESTs (Table 2).

As no genomic sequence was present in GenBank for the ge36 cDNA, we obtained the sequence of 11 exons by directly sequencing BACs 211P21 and 112B20 using primers based on the CDNA sequence (GenBank Accession Nos. AF 297016-AF297023 and AF 312863). The second exon, seen in only one EST (GenBank Accession No. Al041091), is part of an Alu repeat and is usually spliced out.

While examining the genomic structure of the ell CDNA, we noted the presence of a polymorphic AluSb2 sequence (Batzer et al., 1995) in the first intron of ell. This sequence is present in the BAC $120 \mathrm{~K} 12 \mathrm{se}-$ quence (GenBank Accession No. AL 109865) and absent in the unfinished sequence of BAC 98H 19 (GenBank Accession No. AL 109956). The sequence appears to be a recent insertion as it is flanked by a perfect 16-base direct repeat (GTGAGTTGTGATTTCT), only one copy of which is present in $98 \mathrm{H} 19$. The more recently finished sequence of $98 \mathrm{H} 19$ shows no evidence of the insertion since finishing was performed to an overlap of only 100 bases. The existence of the insertion was confirmed by direct PCR of the two BACs with primers (AAAGAAGTTTTTCATCAAGACCAGGGCT and GGAAACAGGAGAAAGAGGGTCCACTATG) flanking the insertion. Subsequent analysis of 19 affected individuals from 10 prostate cancer families found 6 of 38 chromosomes containing the insertion (16\%), whereas only 2 of 132 chromosomes from unmatched CEPH controls contained the insertion (1.5\%). Further anal- 
ysis is required to determine the statistical significance of these data. A number of recently arisen Alu insertion polymorphisms have been reported to show very different allele frequencies in different ethnic populations (Milewicz et al., 1996; Roy et al., 2000).

\section{DISCUSSION}

The critical step in gene identification following linkage analysis is to build a saturated transcript map of the implicated region and to characterize all potential transcripts for their expression profiles and putative biological functions in the cell. Such regional transcript maps also contribute toward the ultimate goal of the Human Genome Project, which is to identify all genes encoded by the human genome (Collins et al., 1998). The 1 q25 region flanked proximally by D1S466 and distally by D1S1642 represents approximately $6 \mathrm{Mb}$ of genomic DNA and harbors the disease loci for prostate cancer (HPC1), camptodactyly-arthropathy-coxa vara-pericarditis syndrome (CACP; Bahabri et al., 1998), and the hyperparathyroidism-jaw tumor syndrome. Recently, we identified mutations in the MSF gene mapped to this region (GenBank Accession No. NM-005807) in CACP patients (Marcelino et al., 1999).

Here we present data on characterization of 37 potential transcripts mapping to this region. To recognize the full coding potential of this region, we used an approach consisting of expression-independent methods, such as exon-trapping and sample sequencing, in conjunction with the human gene map information from the public database. It is worthwhile to note that three transcripts, RGS8, ge36, and ge42, were initially identified by exon traps only. There is still no EST overlapping with RGS8, whereas ge36 (Unigene cluster Hs. 112017) and ge42 (No Unigene cluster) have unmapped ESTs and, therefore, could have been missed as transcripts mapping to this region by using gene map databases alone. Similarly the CACP gene was identified as mapping to this region through sample sequencing of a BAC clone. These results highlight the need to combine various methods of transcript detection to recognize the full coding potential of a given genomic region.

Our transcript characterization strategy was dictated by our primary interest in the HPCl gene. There fore, the first level of prioritization based on expression profiling of 37 potential transcripts led us to pursue 22 of these further. Of these, we have identified 10 novel transcripts expressed in prostate. Although none of these transcripts is exclusively or predominantly expressed in prostate, they represent potential candidates for HPC1. Since parathyroid expression was not tested in this study, all novel transcripts as well as the ESTs not characterized here should be screened for their expression in parathyroid, kidney, and other appropriate tissues to identify potential candidates for the HRPT2 syndrome. Of the 22 transcripts chosen based on Northern blot data, 14 represented 13 novel transcripts, 2 represented artifacts of cDNA cloning, 2 represented the human homologue of rat RGS8, 1 represented the human homologue of him-4 (Manuscript in preparation), 1 represented the human homologue of mouse RGL (Sood et al., 2000), and 2 represented known genes.

RGS8 is a member of a superfamily of evolutionarily conserved proteins involved in the regulation of $\mathrm{G}$ protein-dependent signaling (Dohlman and Thorner, 1997). To date, more than 20 members of the RGS family (named for its function) have been described. These proteins share a sequence of approximately 120 amino acids, called the RGS domain, that is responsible for their GTPase-activating protein activity and also contain a nuclear localization signal. However, the RGS proteins localize differentially within cells as a result of differences in their amino-terminal sequences (Chatterjee and F isher, 2000). These genes also display distinct patterns of expression (Beadling et al., 1999), which in combination with differential localization within the cell is, presumably, an important means to control RGS function. The rat RGS8 gene has been shown to be a neural-tissue-specific transcript that accelerates the modulation of G-protein-coupled channels and thus might be involved in the rapid regulation of neuronal excitability upon stimulation of G-proteincoupled receptors (Saitoh et al., 1997). Our analysis of the human homologue of the RGS8 gene shows it to be a neural-tissue specific transcript also. Two alternate forms of human RGS8 with different amino-terminal sequences and, presumably, different promoters might add a further level of control on their function in the neural tissues.

Of the 13 novel transcripts, we have cloned fulllength CDNAs for 9 transcripts. This is evident from either the presence of an in-frame upstream termination codon or the presence of a Kozak consensus sequence and concordance between the expected sizes from the Northern blot data and the cloned length of the transcripts. Several of the proteins encoded by the novel transcripts are fairly large, e.g., greater than 900 amino acids for ell, el5, and el6.

No deductions could be made for the putative biological roles of c48/KIAA0250, e17, and e8/c24, due to the lack of any similar sequences of known function or robust sequence motifs that would suggest a function. The remaining novel transcripts demonstrated varying levels of homologies to predicted and cloned genes from mouse, rat, Drosophila, C. el egans, and yeast (Table 2). In most cases, the homology is either too weak or limited to too small a segment of the protein to make any inferences about function without further studies. However, a few of the proteins have features that suggest a potential function.

ge42 contains one or two $\mathrm{C} 2 \mathrm{H} 2$ zinc finger domains as well as a tRNA methyltransferase domain, which suggests that it may be involved in the methylation of nucleic acids. c33/c47/KIAA0584 has substantial homology to two human proteins encoded by AF 177203 
(which is a carboxyl extension of KIAA1502) and AK 025982. These proteins are apparently 100 and 380 amino acids shorter than c33/c47/KIAA0584 and align with it with minimal gaps over their whole length including a conserved carboxyl-terminal motif, RDEL, which is a minor variant of the endoplasmic reticulum targeting signal, which is prototypically KDEL. Starzyk et al. (2000) have identified AF 177203 as encoding a cerebral cell adhesion molecule that supports leukocyte adhesion although it is not clear how to reconcile this function with possible sequestration in the lumen of the endoplasmic reticulum.

ge36 has significant but scattered homology to the murine protein PAL, a novel protein expressed in proliferating cells, which binds to the $\mathrm{SH} 2$ domain of Shc (Schmandt et al., 1999). Shc in turn binds to tyrosinephosphorylated proteins and plays a role in signaling by receptors with tyrosine kinase activity. Thus one might suppose that ge36 plays a role in the same signaling pathways.

C112 has no significant homology with any eukaryotic proteins but has $30-40 \%$ homology to various prokaryotic $\mathrm{N}$-acetylneuraminate lyase (EC4.1.3.3) proteins and roughly $30 \%$ homology to prokaryotic dihydrodipicolinate synthases, which extends over essentially the full length of both c112 and the prokaryotic proteins without substantial gap insertions. As both proteins have similar structures (Mirwaldt et al., 1995) and use pyruvate as a substrate, it is likely that c112 will have a similar enzymatic function.

Finally, transcript identification and cloning have recently moved from wet lab to in sili co approaches due to the availability of genomic sequences and a variety of gene-prediction programs (Stormo, 2000). Validation of such an approach is required to make sure that the entire coding potential of the human genome will be identified. Since a minimal tiling path of BAC clones representing the entire 6-Mb region is currently being sequenced at the Sanger Centre, it will be interesting to see whether all transcripts cloned during this study will be recognized by gene prediction and whether all exons of a transcript can be predicted precisely. The presence of partial protein sequences in GenBank for el1, e16, and ge42 derived from genomic sequences using gene prediction approaches suggests that such an approach is feasible but requires better programs to identify the ends of transcripts. Furthermore, our cDNA clones provide a tangible source that can be used in the laboratory to ask questions about their biological roles in the cell.

This study provides a resource of several candidate genes for HPC1 and HRPT2 syndrome. At least 10 transcripts are identified as potential candidates for prostate cancer based on their expression pattern data. In the absence of functional data on these genes, further prioritization is difficult. Therefore, evaluation of these genes as candidates requires mutational analysis, and we are currently performing mutational analysis using single-stranded conformational polymor- phism and direct sequencing of exons using CDNA and genomic DNA, respectively, from patients from families showing linkage to the 1q25 region to identify the disease-associated mutations.

\section{ACKN O WLEDG MENTS}

The authors thank Darryl Leja for outstanding assistance with artwork. This work was supported through the National Human Genome Research I nstitute I ntramural Program.

\section{REFERENCES}

Ahman, A.-K., J onsson, B.-A., Damber, J .-E., Bergh, A., Emanuelsson, M., and Gronberg, H. (2000). Low frequency of allelic imbalance at the prostate cancer susceptibility loci HPC1 and 1p36 in Swedish men with hereditary prostate cancer. Genes Chromosomes Cancer 29: 292-296.

Altschul, S. F., Gish, W., Miller, W., Myers, E. W., and Lipman, D. (1990). Basic local alignment search tool. J . Mol. Biol. 215: 403410.

Bahabri, S. A., Suwairi, W. M., Laxer, R. M., Polinkovsky, A., DaIaan, A. A., and Warman, M. L. (1998). The camptodactyly-arthropathy- coxa vara-pericarditis syndrome: Clinical features and genetic mapping to human chromosome 1. Arthritis Rheum. 41: 730-735.

Batzer, M. A., Rubin, C. M., Hellmann-Blumberg, U., Alegria-Hartman, Leeflang, E. P., Stern, J. D., Bazan, H. A., Shaikh, T. H., Deininger, P. L., and Schmid, C. W. (1995). Dispersion and insertion polymorphism in two small subfamilies of recently amplified human Alu repeats. J. Mol. Biol. 247: 418- 427.

Beadling, C., Druey, K. M., Richter, G., Kehrl, J . H., and Smith, K. A. (1999). Regulators of $G$ protein signaling exhibit distinct patterns of gene expression and target $G$ protein specificity in human lymphocytes. J . Immunol. 162: 2677-2682.

Beaudoing, E., Freier, S., Wyatt, J . R., Claverie, J .-M., and Gautheret, D. (2000). Patterns of variant polyadenylation signal usage in human genes. Genome Res. 10: 1001-1010.

Berry, R., Schroeder, J . J ., French, A. J ., McDonell, S. K., Peterson, B. J., Cunningham, J. M., Thibodeau, S. T., and Schaid, D. J. (2000). Evidence for a prostate cancer-susceptibility locus on chromosome 20. Am. J. Hum. Genet. 67: 82-91.

Berthon, P., Valeri, A., Cohen-Akenine, A., Drelon, E., Paiss, T., Wohr, G., Latil, A., Millasseau, P., Mellah, I., Cohen, N., Blanche, H., Bellane-Chantelot, C., Demenais, F., Teillac, P., Le Duc, A., de Petriconi, R., Hautmann, R., Chumakov, I., Bachner, L., Maitland, N. J ., Lidereau, R., Vogel, W., Fournier, G., Mangin P., Cohen, D., and Cussenot, O. (1998). Predisposing gene for early-onset prostate cancer, localized on chromosome 1q42.2-43. Am. J. Hum. Genet. 62: 1416-1424.

Carpten, J. D., Makalowska, I., Robbins, C. M., Scott, N., Sood, R., Connors, T. D., Bonner, T. I., Smith, J. R., Faruque, M. U., Stephan, D. A., Pinkett, H., Morgenbesser, S. D., Su, K., Graham, C., Gregory, S. G., Williams, H., McDonald, L., Baxevanis, A. D., Klinger, K. W., Landes, G. M., and Trent, J. M. (2000). A 6-Mb high-resolution physical and transcription map encompassing the hereditary prostate cancer 1 (HPC1) region. Genomics 64: 1-14, doi: 10.1006/geno.1999.6051.

Chatterjee, T. K., and Fisher, R. A. (2000). Cytoplasmic, nuclear, and Golgi localization of RGS proteins-Evidence for $\mathrm{N}$-terminal and RGS domain sequences as intracellular targeting motifs. J . Biol. Chem. 275: 24013-24021.

Cher, M. L., Bova, G. S., Moore, D. H., Small, E. J ., Carroll, P. R., Pin, S. S., Epstein, J . I., I saccs, W. B., and J ensen, R. H. (1996). Genetic alterations in untreated metastases and androgen-independent 
prostate cancer detected by comparative genomic hybridization and allel otyping. Cancer Res. 56: 3091-3102.

Collins, F. S., Patrinos, A., J ordan, E., Chakravarti, A., Gesteland, R., Walters, L., and the members of the DOE and NIH planning groups (1998). New goals for the U.S. Human Genome Project: 1998-2003. Science 282: 682- 689.

Cooney, K. A., McCarthy, J . D., Lange, E., Huang, L., Miesfeldt, S., Montie, J. E., Oesterling, J. E., Sandler, H. M., and Lange, K. (1997). Prostate cancer susceptibility locus on chromosome 1q: A confirmatory study. J . Natl. Cancer Inst. 89: 955-999.

Deloukas, P., Schuler, G. D., Gyapay, G., Beasley, E. M., Soderlund, C., Rodriguez-Tome, P., Hui, L., Matise, T. C., McKusick, K. B., Beckman, J. S., Bentolila, S., Bihoreau, M.-T., Birren, B. B., Browne, J ., Butler, A., Castle, A. B., Chiannilkulchai, N., Clee, C., Day, P. J. R., Dehejia, A., Dibling, T., Drouot, N., Duprat, S., Fizames, C., Fox, S., Gelling, S., Green, L., Harrison, P., Hocking, R., Holloway, E., Hunt, S., Keil, S., Lijnzaad, P., Louis-Dit-Sully, C., Ma, J ., Mendis, A., Miller, J ., Morissette, J ., Muselet, D., Nusbaum, H. C., Peck, A., Rozen, S., Simon, D., Slonim, D. K., Staples, R., Stein, L. D., Stewart, E. A., Suchard, M. A., Thangarajah, T., Vega-Czarny, N., Webber, C., Wu, X., Hudson, J., Auffray, C., Nomura, N., Sikela, J. M., Polymeropoulos, M. H., J ames, M. R., Lander, E. S., Hudson, T. J ., Myers, R. M., Cox, D. R., Weissenbach, J ., Boguski, M. S., and Bentley, D. R. (1998). A physical map of 30,000 human genes. Science 282: 744-746.

Dohlman, H. G., and Thorner, J . (1997). RGS proteins and signaling by heterotrimeric G proteins-Minireview. J. Biol. Chem. 272: 3871-3874.

Dunsmuir, W. D., Edwards, S. M., Lakhani, S. R., Young, M., Corbishley, C., Kirby, R. S., Dearnaley, D. P., Dowe, A., Ardern-J ones, A., and Kelly, J . (1998). Allelic imbalance in familial and sporadic prostate cancer at the putative human prostate cancer susceptibility locus, HPC1. Br. J . Cancer 78: 1430-1433.

Gibbs, M., Stanford, J . L., Mclndoe, R. A., J arvik, G. P., Kolb, S., Goode, E. L., Chakrabarti, L., Schuster, E. F., Buckley, V. A., Miller, E. L., Brandzel, S., Hood, L., and Ostrander, E. A. (1999). Evidence for a rare prostate cancer-susceptibility locus at chromosome 1p36. Am. J . Hum. Genet. 64: 1087-1095.

Hobbs, M. R., Pole, A. R., Pidwirny, G. N., Rosen, I. B., Zarbo, R. J ., Coon, H., Heath, H., III, Leppert, M., and J ackson, C. E. (1999). Hyperparathyroidism-jaw tumor syndrome: The HRPT2 locus is within a $0.7-c M$ region on chromosome 1q. Am. J . Hum. Genet. 64: 518-525.

Kolbinger, F., Streiff, M. B., and Katopodis, A. G. (1998). Cloning of a human UDP-galactose: 2-Acetamido-2-deoxy-D-glucose 3 $\beta$-galactosyltransferase catalyzing the formation of type 1 chains. J . Biol . Chem. 273: 433- 440.

Kozak, M. (1996). Interpreting cDNA sequences: Some insights from studies on translation. Mamm. Genome 7: 563-574.

Latil, A., Cussenot, O., Fournier, G., and Lidereau, R. (1997). Infrequent allelic imbalance at the major susceptibility HPC1 locus in sporadic prostate tumors. Int. J . Cancer 71: 1118.

Marcelino, J., Carpten, J. D., Suwairi, W. M., Gutierrez, O. M., Schwartz, S., Robbins, C., Sood, R., Makalowska, I., Baxevanis, A., J ohnstone, B., Laxer, R. M., Zemel, L., Kim, C. A., Herd, J . K., I hle, J ., Williams, C., J ohnson, M., Raman, V., Alonso, L. G., Brunoni, D., Gerstein, A., Papadopoulos, N., Bahabri, S. A., Trent, J . M., and Warman, M. L. (1999). CACP, encoding a secreted proteoglycan, is mutated in camptodactyly-arthropathy- coxa vara-pericarditis syndrome. Nat. Genet. 23: 319-322.

Milewicz, D. M., Byers, P. H., Reveille, J ., Hughes, A. L., and Duvic, M. (1996). A dimorphic Alu Sb-like insertion in COL $3 A 1$ is ethnicspecific. J . Mol. Evol. 42: 117-123.

Mirwaldt, C., Korndorfer, I ., and Huber, R. (1995). The crystal structure of dihydrodipicolinate synthase from Escherichia coli at 2.5 ÅA resolution. J. Mol. Biol. 246: 227-239.
Nagase, T., Seki, N., I shikawa, K., Ohira, M., Kawarabayasi, Y., Ohara, O., Tanaka, A., Kotani, H., Miyajima, N., and Nomura, N. (1996). Prediction of the coding sequences of unidentified human genes. VI. The coding sequences of 80 new genes (KIAA0201KIAA 0280) deduced by analysis of CDNA clones from cell line KG-1 and brain. DNA Res. 3: 321-329.

Nagase, T., Ishikawa, K., Miyajima, N., Tanaka, A., Kotani, H., Nomura, N., and Ohara, O. (1998). Prediction of the coding sequences of unidentified human genes. IX. The complete sequences of 100 new cDNA clones from brain which can code for large proteins in vitro. DNA Res. 5: 31-39.

Neuhausen, S. L., Farnham, J. M., Kort, E., Tavtigian, S. V., Skolnick, M. H., and Cannon-Albright, L. A. (1999). Prostate cancer susceptibility locus HPClin Utah high-risk pedigrees. Hum. Mol. Genet. 8: 2437-2442.

Ohara, O., Nagase, T., Ishikawa, K., Nakajima, D., Ohira, M., Seki, N., and Nomura, N. (1997). Construction and characterization of human brain cDNA libraries suitable for analysis of CDNA clones encoding relatively large proteins. DNA Res. 4: 53-59.

Rebbeck, T. R., Walker, A. H., Zeigler-J ohnson, C., Weisbutg, S., Martin, A.-M., Nathanson, K. L., Wein, A. J ., and Malkowicz, S. B. (2000). Association of HPC2/ELAC2 genotypes and prostate cancer. Am. J . Hum. Genet. 67: 1014-1019.

Robbins, C. M., Hsu, E., and Gillevet, P. M. (1996). Sequencing homopolymer tracts and repetitive elements. Biotechniques 20: 862-868.

Roy, A. M., Carroll, M. L., Nguyen, S. V., Salem, A.-H., Oldridge, M., Wilkie, A. O. M., Batzer, M. A., and Deininger, P. L. (2000). Potential gene conversion and source genes for recently integrated Alu elements. Genome Res. 10: 1485-1495.

Saitoh, O., Kubo, Y., Miyatani, Y., Asano, T., and Nakata, H. (1997). RGS8 accelerates G-protein-mediated modulation of $\mathrm{K}^{+}$currents. Nature 390: 525-529.

Sattler, H.-P., Rohde, V., Bonkhoff, H., Zwergel, T., and Wullich, B. (1999). Comparative genomic hybridization reveals DNA copy number gains to frequently occur in human prostate cancer. Prostate 39: 79-86.

Schmandt, R., Liu, S. K., and McGlade, C. J . (1999). Cloning and characterization of $\mathrm{MPAL}$, a novel Shc $\mathrm{SH} 2$ domain-binding protein protein expressed in proliferating cells. Oncogene 18: 18671879.

Smith, J . R., Freije, D., Carpten, J . D., Gronberg, H., Xu, J ., I saacs, S. D., Brownstein, M. J., Bova, G. S., Guo, H., Bujnovszky, P., Nusskern, D. R., Damber, J .-E., Bergh, A., Emanuelsson, M., Kallioniemi, O. P., Walker-Daniels, J., Bailey-Wilson, J. E., Beaty, T. H., Meyers, D. A., Walsh, P. C., Collins, F. S., Trent, J . M., and Isaacs, W. B. (1996). Major susceptibility locus for prostate cancer on chromosome 1 suggested by a genome-wide search. Science $\mathbf{2 7 4}$ 1371-1374.

Sood, R., Makalowska, I., Carpten, J . D., Robbins, C. M., Stephan, D. A., Connors, T. D., Morgenbesser, S. D., Su, K., Pinkett, H. W., Graham, C. L., Quesenberry, M. I., Baxevanis, A. D., Klinger, K. W., Trent, J. M., and Bonner, T. I. (2000). The human RGL (RalGDS-like) gene: Cloning, expression analysis and genomic organization. Biochem. Biophys. Acta 1491: 285-288.

Starzyk, R. M., Rosenow, C., Frye, J ., Leismann, M., Rodzinski, E., Putney, S., and Tuomanen, E. I. (2000). Cerebral cell adhesion molecule: A novel leukocyte adhesion determinant on blood- brain barrier capillary endothelium. J . Infect. Dis. 181: 181-187.

Stormo, G. D. (2000). Gene-finding approaches for eukaryotes. Ge nome Res. 10: 394-397.

Suarez, B. K., Lin, J ., Burmester, J . K., Broman, K. W., Weber, J . L., Banerjee, T. K., Goddard, K. A. B., Witte, J. S., Elston, C., and Catalona, W. J . (2000). A genome screen of multiple sibships with prostate cancer. Am. J . Hum. Genet. 66: 933-944.

Teh, B. T., Farnebo, F., Kristoffersson, U., Sundelin, B., Cardinal, J ., Axelson, R., Yap, A., Epstein, M., Heath, H., III, Cameron, D., and Larsson, C. (1996). Autosomal dominant primary hyperparathy- 
roidism and jaw tumor syndrome associated with renal hamartomas and cystic kidney disease: Linkage to 1q21- q32 and loss of the wild type allele in renal hamartomas. J . Clin. Endocr. Metab. 81: 4204- 4211.

Visakorpi, T., Kallioniemi, A. H., Syvanen, A. C., Hyytinen, E. R., Karhu, R., Tammela, T., I sola, J . J ., and Kallioniemi, O. P. (1995). Genetic changes in primary and recurrent prostate cancer by comparative genomic hybridization. Cancer Res. 55: 342-347.

Williamson, C., Cavaco, B. M., J ausch, A., Dixon, P. H., Forbes, S., Harding, B., Holtgreve-Grez, H., Schoell, B., Pereira, M. C., Font, A. P., Loureiro, M. M., Sobrinho, L. G., Santos, M. A., and Thakker, R. V. (1999). Mapping the gene causing hereditary primary hyperparathyroidism in a Portuguese kindred to chromosome 1q22- q31. J . Bone Miner. Res. 14: 230-239.
Wolfsberg, T. G., and Landsman, D. (1997). A comparison of expressed sequence tags (ESTs) to human genomic sequences. Nucleic Acids Res. 25: 1626-1632.

Xu, J ., Meyers, D., Freije, D., I saacs, S., Wiley, K., Nusskern, D., Ewing, C., Wilkens, E., Piroska, B., Bova, G. S., Walsh, P., Isaacs, W., Schleutker, J., Matikainen, M., Tammela, T., Visakorpi, T., Kallioniemi, O. P., Ewing, C., Berry, R., Schaid, D., French, A., McDonnell, S., Schroeder, J ., Blute, M., Thibodeau, S., Gronberg H., Emanuelsson, M., Damber, J .-D., Anders, B., J onsson, B.-A., Smith, J., Bailey-Wilson, J ., Carpten, J ., Stephan, D., Gillanders, E., Asmundson, I., Kainu, T., Freas-Lutz, D., Baffoe-Bonnie, A., Van Aucken, A., Sood, R., Collins, F., Brownstein, M., and Trent, J . M. (1998). Evidence for a prostate cancer susceptibility locus on the X chromosome. Nat. Genet. 20: 175-179. 